\title{
Trends and Improvement of the Institutional Mechanism of Land Rent in Sustainable Development
}

\author{
Olesya Ivanenko ${ }^{1}$, Aleksandr Kovalev ${ }^{1}$, and Vasiliy Kovalev ${ }^{1}$ \\ ${ }^{1}$ Financial University under the Government of the Russian Federation, Omsk Branch, 644099 \\ Partizanskaya st. 6, Omsk, Russia
}

\begin{abstract}
At present, one of the priority tasks of implementing state economic policy is to promote the sustainable development, including the means of agriculture. In the article, the authors revealed the essence of land rent as an institution and identified the need to study the institutional mechanism of land rent in the agricultural sector as a way of regulating the economic activities of landowners, land users and the state in transition to sustainable development. Based on the identified development trends, an algorithm has been developed to improve the institutional mechanism that ensures the effective functioning of the institution of land rent. The conceptual approach proposed in the study can be used as a theoretical and methodological basis for sustainable development and improvement of rental policies in Russian agriculture.
\end{abstract}

\section{Introduction}

In the course of ongoing market reforms in Russian agriculture, the economic conditions significantly transformed, a different sphere of activity of the company was formed, characterized by a variety of forms of ownership, market principles of work, a change in customs, traditions, and mentality of the population. As a result, issues of improving rental relations and the distribution of rental income between society and business entities came to the fore, not only with a view to replenishing the budget, but also stimulating economic activity and protecting the interests of the population. The experience of developed countries suggests that a well-functioning rental tax system can ensure the efficient use of natural resources and equal economic conditions (regardless of the effect of the natural factor), and stimulate intensive economic growth [1].

The practice of Russian reforms has shown that the degree of their effectiveness is largely determined by the level of development of institutions. Therefore, this factor was recognized as the determining success of transformations, both in theoretical and in practical terms. This is especially relevant for the Russian agro-industrial complex. Ignoring the institutional restrictions specific to agricultural production, such as a short production cycle, high production risks, different fertility and location of land plots, weather conditions, traditions of communal land tenure, rural mentality, underdevelopment and ambiguity of the legislative base led to a significant reduction in the efficiency of agricultural production. In this regard, for the agrarian sector of the modern Russian economy, the formation and development of 
agricultural institutions, including the institution of land rent, is of particular importance for economic research.

The institution as an object of research is a phenomenon that accompanies the evolution of economic systems and has no analogue in the inanimate world. This concept developed along with the development of individuals and organizations, as well as the conditions for their functioning. The science provides many definitions of the institute, we give some of them:

- economics interprets institutions as explicitly or implicitly defined restrictions that subordinate the actions of a rational subject of economic activity;

- within the framework of the old institutionalism, the institute includes cultural norms, faith, mentality and is treated as a socio-psychological phenomenon;

- representatives of the new institutional economy treat institutions as formalized rules and unformalized norms of behavior that structure interactions between individuals within the framework of economic systems;

- the latest institutional approach also defines institutions as "rules of the game"; however, in this case, the concepts of institution and organization are clearly divided;

- institution also can be an organizational structure, for example, financial and credit institutions - agricultural credit cooperatives, insurance companies.

Thus, institutions are created with the aim of providing direction and forecasting the actions of people. They allow you to adapt to external factors that are impossible to manage and resolve recurring situations. This not only solves the problem, but also minimizes the costs associated with resolving the problem.

\section{Materials and Methods}

Given the priority of the institutional approach in solving the problems of formation, withdrawal and distribution of rents, in this paper we take the definition of land rent as an institution, which refers to a combination of various formal and informal norms and rules, as well as enforcement mechanisms, the use of which streamlines and strategically orientates owners of land, as well as the state in establishing mutual relations arising in the process of formation, extraction, distribution and use of rental income.

At the same time, the establishment and development of the institution of land rent in agriculture in Russia, as a complex of certain formal and informal norms and rules, requires a special mechanism for their implementation. Such a mechanism is the institutional mechanism of land rent, the purpose of which is to regulate the activities of the institution in question, which can be interpreted as establishing and monitoring compliance with the rules. The essence of the institutional mechanism is manifested in its functions. Based on the presented classification of functions O.V. Inshakov and N.N. Lebedeva [2], the authors identified the following specific functions of the institutional mechanism of land rent (Fig. $1)$ :

The institutional mechanism of land rent is an evolving mechanism; its functional content changes under the influence of new information, the transformation of goals and objectives, the emergence of new norms and rules, which, in turn, affects the functions and content that it acquires in the process of its development.

Therefore, the institutional mechanism of land rent acts as an ordered system for regulating the economic activity of land owners, tenants and the state, formed by the internal nature of the institution of land rent. It is that "collective good" that contributes to the streamlining, formalization and standardization of land rent relations, creates organizational and economic conditions for the stable operation of subjects of the institution of land rent, legislatively consolidates the emerging relations of land rent, contributes to the effective implementation of the goals and objectives set by the economic mechanism [3]. 


\begin{tabular}{l} 
Functions of the \\
institutional \\
mechanism of land the unification of the main subjects of land rent relations within the framework of the institution of \\
land rent and the determination of their role in joint activities through common norms and rules; \\
rent: \\
2) legislative consolidation of emerging rental relations \\
3) informing the subjects of rental relations about the accepted norms, as well as about opportunistic \\
behavior; \\
$\begin{array}{l}\text { 4) regulation of the interaction of subjects of relations of land rent upon entry into institutional } \\
\text { structures; }\end{array}$ \\
$\begin{array}{l}\text { 5) reducing the degree of uncertainty and facilitating the coordination of subjects of the institution of } \\
\text { land rent; }\end{array}$ \\
$\begin{array}{l}\text { 6) monitoring the implementation of the norms and rules of the institution of land rent in order to } \\
\text { increase the efficiency of its functioning; }\end{array}$ \\
$\begin{array}{l}\text { 7) the search for institutional contradictions and traps in the implementation of the norms and rules of } \\
\text { the institution of land rent; }\end{array}$ \\
8) ensuring the modification of the institute using special methods, tools, tools and forms. \\
\hline
\end{tabular}

Fig. 1. The specific functions of the institutional mechanism of land rent.

\section{Results and Discussion}

When studying the institutional mechanism of land rent, the authors identified the following trends in its development:

Firstly, a rather mixed situation has arisen with the assessment of rental income. In this situation, land rental payments do not fully reflect the true size of land rents. Under these conditions, the main rent defining factors are prices for agricultural products, which vary widely across regions, and the level of which is affected by changing and often conflicting market conditions, regional features, etc. This leads to a violation of their stability and does not allow to justify forecasts on the levels of rents. More and more often, assignment ceases to enter the system of rental relations; rental income distribution is skewed - most of the rent goes beyond the region.

Secondly, the land reform has contributed to the expansion of the system of subjects of rental relations, which are currently large and medium-sized agricultural enterprises, tenants and farmers. However, the integration processes taking place in the agricultural sector of the Russian economy, and accompanied by the separation of the owner from the main means of production - the land, lead to the unification of land by agricultural holdings and other entities. Thus, over time, the subjects of appropriation of rents become larger and smaller, and small and medium-sized agricultural organizations and individual farmers lose their chances of obtaining rental income.

Thirdly, the legislative and regulatory support of rental relations is not corresponding reality. The institutional mechanism of land rent is still not based on a scientifically proved concept of land rent relations and an adequate rental component of this mechanism. There are no legislative acts that include scientific principles and legal norms for accounting for rent, and, based on international experience, standards for its distribution between business entities and the state, including progressive rates of rental tax that is withdrawn from profits above the optimal level of profitability are not represented in the legislation [4].

Fourth, the imperfection of the legislative framework, as well as the contradictions that arise between informal and formal norms, lead to the emergence of such a thing as an "institutional trap". This institutional phenomenon is a manifestation of persistent contradictions arising in the course of the state changing the content of formal institutions [57]. As institutional traps for the agrarian sector of Russia, one can consider the behavior of subjects in the process of involving land plots in rental relations, as well as the seizure of land rent through land tax. Due to the lack of a legal ground for lease relations, which leads to a violation of the rights of subjects of these relationships and contractual obligations, rent for land is not an effective tool for extracting and distributing rents. The most important in 
this case is the land tax. However, at the same time, its percentage in the total tax payments of agricultural organizations is insignificant, which does not allow it to be the motive for more efficient use of land.

Fifthly, at present, the need has arisen to preserve and rationally exploit rent-forming resources in the agricultural sector. Land tenure, which is irrational from the point of view of the environmental interests of society, is primarily due to the system of institutional determinants that determine the formation of "temporary worker" psychology in the subjects of rent relations. This is due to the underdevelopment of the information and consulting infrastructure of the land market, the lack of reliability and completeness of information about the subjects of rental relations, the presence of administrative barriers to land tenure and land use, incomplete ownership of land, inefficient use of common shared ownership of the land due to the lack of effective organizational forms of cooperation of equity holders [8-10].

So, as a result of the analysis of the development of the institutional mechanism of land rent, the authors identified the following socio-economic problems of its functioning: inconsistency and insufficient elaboration of the legal framework, inefficiency of economic instruments, insufficient development of organizational and procedural tools, negative influence of mental tools, which allowed us to conclude that it is necessary to improve it [1112]. We propose to change and improve the institutional mechanism of land rent in the following stages (Fig. 2).

The first stage involves monitoring and analysis of the existing system of informal tools of the institutional mechanism of land rent. The objective of this stage is to assess the extent of distribution and the level of functioning of the informal constraint. The main purpose of such an assessment is to determine the economic and social effect of using the appropriate restriction or norm. On the one hand, informal tools are characterized by a high degree of support in the public consciousness, because of which any transformations should take into account already existing stereotypes of thinking and behavior in society, the rooted mechanism of rent relations.

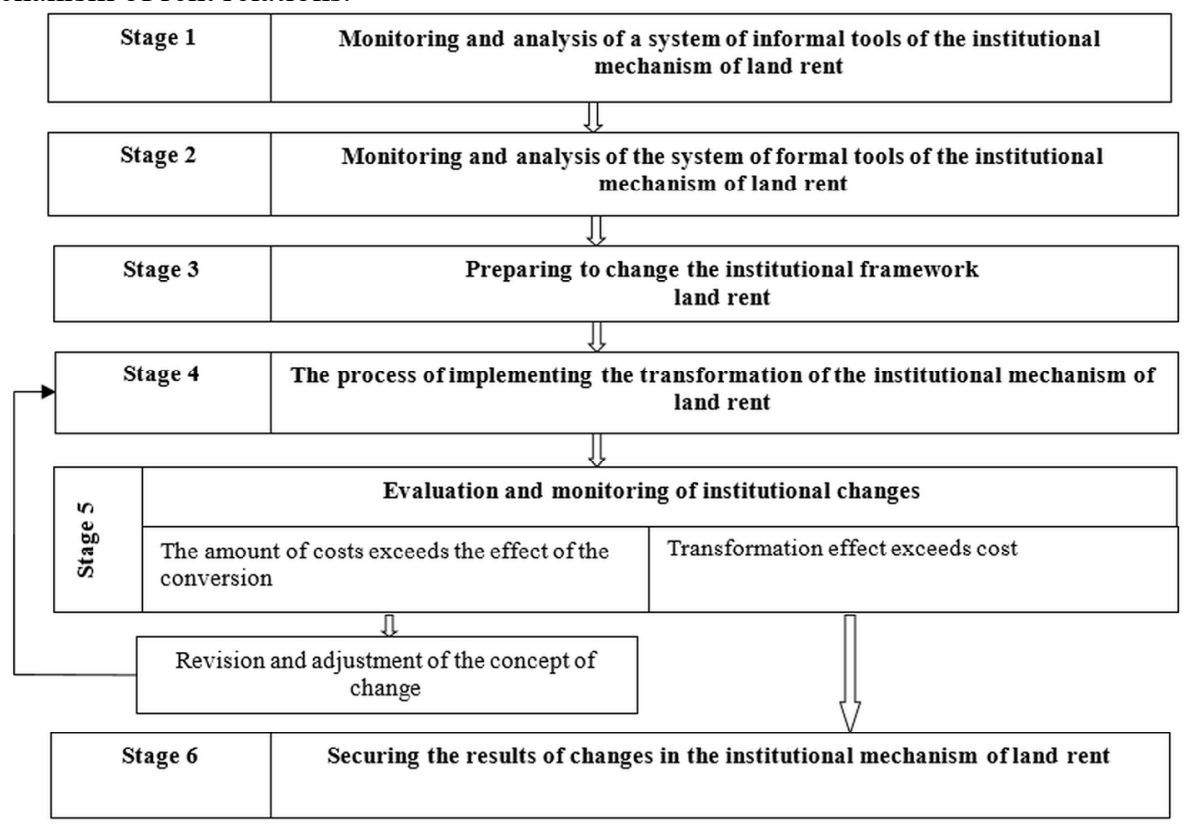

Fig. 2. Algorithm for improving the institutional mechanism of land rent.

On the other hand, the peculiarity of institutional restrictions is such that violation of the institutional mechanism based on informal restrictions brings income to certain subjects of 
rental relations. In particular, fines for non-compliance with environmental requirements, violation of tax laws, are significantly less compared to the benefits that an entity can receive if this restriction is not observed.The manifestation of this specificity leads to functional disorders within the institutional mechanism of land rent, to an ineffective interaction of its subjects. Therefore, for the effective implementation of this stage, a thorough analysis of the nature of the relationship between informal constraints and alternative formal norms is required.

At the second stage, monitoring and analysis of the system of formal tools for the functioning of the mechanism is carried out, including the benefits and costs of observing the regulatory framework governing rental relations are calculated, in particular, the sale, lease, pledge of land, guaranteed rights to receive rental income, and the definition of boundaries of federal, regional and municipal land ownership. It should be noted that the priority analysis of informal constraints over formal instruments is in developing and coordinating elements of the institutional mechanism, since formal constraints have a chance to gain a foothold only if they are congruent with the general direction, albeit slowly, but still changing informal instruments. The implementation of the first two stages will reveal the shortcomings in the functioning of the existing institutional mechanism, its strengths and weaknesses, as well as identify trends and directions for its improvement.

The third stage involves preparing for a change in the institutional mechanism of land rent. At this stage, a search for "common ground" of norms and rules in the new circumstances is carried out, the degree of their congruency is assessed. Changes in formally applicable norms should occur under the influence of the most effective and widespread informal components of the institutional mechanism. Also at this stage, the effectiveness of this interaction is evaluated. Moreover, the assessment of the size of the costs associated with the changes should take into account not only the economic efficiency of the expected results, but should also be carried out taking into account the degree of social satisfaction of the population with these changes.

The fourth stage is associated with the implementation of the process of transformation of the institutional mechanism of land rent. At this stage, it seems necessary to analyze and give a scientific justification for the possibility of interaction of the changed tools with existing ones, identify new functions of the transformed institutional mechanism, the effectiveness of the interaction between its tools, evaluate the effect that the changes may have on the institution of land rent. When introducing transformations of the institutional mechanism of land rent as a tool to verify its effectiveness, it is possible to conduct an experiment in a particular region, which will minimize errors, identify ineffective tools of this mechanism and exclude their subsequent effect when applied to all economic entities, as well as reduce costs associated with overcoming the negative consequences of the functioning of the mechanism.

The next step in improving the institutional mechanism is the assessment and monitoring of its changes. The main indicator of effectiveness is the assessment of the cost in relation to the level of efficiency of the system as a whole after the implementation of the developed measures in action. An optimal streamlining of the relationships between the subjects of rental relations should help to reduce the level of losses and minimize transaction costs. If the costs of creating new or maintaining existing tools are higher than the benefits, then such tools are unlikely to be created, and if they already exist, they will most likely be ignored. As a result, a revision of the whole concept of change will be required. In the case of a positive result, the transition to the next stage of transformation occurs.

The last stage involves fixing the results of the change. The criteria for the stage are adaptation of transformed tools to changing conditions, monitoring the functioning of both the changed tools and their interrelated ones, as well as the effectiveness of their practical interaction. Such control over the state of the components of the mechanism will prevent the 
emergence of institutional traps that characterize the problem areas of the transformed mechanism. After receiving positive results of the analysis of the functioning system, it is necessary to consolidate the results of institutional changes in the form of relevant regulatory procedures and its public coordination. The final result of this stage will be the procedure for fixing the corresponding results of institutional changes in the form of regulatory procedures and the public coordination of the transformed institutional mechanism of land rent.

\section{Conclusion}

The presented stages structure the process of improving the tools of the institutional mechanism of land rent and are guidelines that emphasize the need for consistent evolutionary development of the tools of this mechanism by conducting an experiment on the interaction of modified tools in an already functioning socio-economic system. Using the developed algorithm will allow us to move on to the institutional mechanism, which allows us to determine the effective framework for the interaction of the institutes of land rent in the agricultural sector (state, landowners and land users) in accordance with its requirements.

The conceptual approach proposed in the study to improve the institutional mechanism of land rent can be used as a theoretical and methodological basis in the development of plans and programs for the implementation of rental policies in agriculture in Russia.

\section{References}

1. A. V. Latkov, Conceptual aspects of the progressive development of Russia (VolSU Publishing, Volgograd, 2006)

2. O. V. Inshakov, N. N. Lebedeva, Typology and classification of institutional mechanisms (VolSU Publishing, Volgograd, 2002)

3. L. V. Grishaeva, O. B. Ivanenko, Institutional mechanism for the implementation of land rent in agriculture (IPC Sfera LLC, Omsk, 2010)

4. I.V. Getmanenko, G.V. Lebedeva, Bulletin of the Agrarian Science of the Don, 4, 92-96 (2010)

5. Yu. A. Pogodin, The Impact of Institutional Change on Economic Growth in Modern Russia (Saratov, SSU Publishing, 2006)

6. A. F. Sagitova, Bulletin of the Chelyabinsk State University. Economic sciences, 56:2, 65$71,(2017)$

7. V. Frolova, O. Dolina, T. Shpilkina, E3S Web of Conf., 105, 01054 (2019)

8. O. Kalenov, S. Kukushkin, R. Kamanina, E3S Web Conf., 105, 04028 (2019)

9. S. Kukushkin, O.Kalenov, E3S Web Conf., 105, 04022 (2019)

10. O. Borisova, V. Frolova, L. Artamonova,E3S Web of Conf., 105, 04047 (2019)

11. E. Dotsenko, N. Ezdina, E3S Web of Conf., 41, 04048 (2018)

12. T. Skryl, E. Shavina, E. Dotsenko, E3S Web Conf., 105, 04049 (2019) 